\title{
Procalcitonin Kinetics in the First 72 Hours Predicts 30- Day Mortality in Severely III Septic Patients Admitted to an Intermediate Care Unit
}

\author{
Filippo Pierallia, b, Vieri Vannucchi ${ }^{\mathrm{a}}$, Antonio Mancini ${ }^{\mathrm{a}}$, Elisa Antoniellia ${ }^{\mathrm{a}}$, Fabio Luise ${ }^{\mathrm{a}}$, \\ Lucia Sammichelia ${ }^{a}$, Valerio Turchi ${ }^{a}$, Ombretta Para ${ }^{a}$, Francesca Bacci ${ }^{a}$, Carlo Nozzoli ${ }^{a}$
}

\begin{abstract}
Background: Severe sepsis and septic shock are leading causes of morbidity and mortality among critically ill patients, thus the identification of prognostic factors is crucial to determine their outcome. In this study, we explored the value of procalcitonin (PCT) variation in predicting 30-day mortality in patients with sepsis admitted to an intermediate care unit.
\end{abstract}

Methods: This prospective observational study enrolled 789 consecutive patients with severe sepsis and septic shock admitted to a medical intermediate care unit between November 2012 and February 2014. Kinetics of PCT expressed as percentage were defined by the variation between admission and 72 hours, and 24 and 72 hours; they were defined as $\Delta$-PCT0-72h and $\Delta$-PCT24-72h, respectively.

Results: The final study group of 144 patients featured a mean age of $73 \pm 14$ years, with a high prevalence of comorbidities (Charlson index greater than 6 in 39\%). Overall, 30-day mortality was $28.5 \%$ (41/144 patients). A receiver-operating-characteristic (ROC) analysis identified a decrease of $\Delta$-PCT0-72h less than $15 \%$ (area under the curve: $0.75 ; 95 \%$ confidence interval (CI): $0.67-0.82$ ) and a decrease of $\Delta$-PCT24-72h less than $20 \%$ (area under the curve: $0.83 ; 95 \% \mathrm{CI}$ : $0.74-0.92)$ as the most accurate cut-offs in predicting mortality. Decreases of $\Delta$-PCT0-72h less than 15\% (HR: 3.9, 95\% CI: $1.6-9.5$; P < 0.0001 ) and $\Delta$-PCT24-72h less than $20 \%$ (HR: $3.1,95 \%$ CI: $1.2-7.9$; $\mathrm{P}<0.001)$ were independent predictors of 30 -day mortality.

Conclusions: Evaluation of PCT kinetics over the first 72 hours is a useful tool for predicting 30-day mortality in patients with severe sepsis and septic shock admitted to an intermediate care unit.

Keywords: Procalcitonin; Sepsis; Biomarker; High dependency unit; Intermediate care unit

Manuscript accepted for publication July 07, 2015

anternal and Emergency Medicine Unit, Careggi University Hospital, Florence, Italy

${ }^{\mathrm{b}}$ Corresponding Author: Filippo Pieralli, Internal and Emergency Medicine Unit, Careggi University Hospital, Largo Brambilla 3, 50134 Firenze, Italy. Email: filpiero@tin.it

doi: http://dx.doi.org/10.14740/jocmr2251w

\section{Introduction}

In recent years, an increasing number of studies have confirmed procalcitonin (PCT) to be one of the most reliable serological markers for bacterial infection and sepsis [1-3]; in particular, its use has become widespread (first in Europe and, recently, in the US since its approval by the FDA in 2006) for differentiating between sepsis and systemic inflammatory response syndrome (SIRS) [3], and guiding empirical antibiotic therapy $[4,5]$ in community-acquired pneumonia and sepsis.

PCT is a 116-amino acid prohormone of the calcium metabolism regulator, calcitonin that is primarily expressed in the thyroid and in extra-thyroidal tissues (neuroendocrine tissue) in response to lipopolysaccharides and bacterially induced cytokines. Being released by parenchymal cells, including the liver cells, adipocytes, and muscle cells [2], plasma PCT levels start to rise within $2-6 \mathrm{~h}$ of initial clinical manifestation of sepsis, and fall if the septic process is controlled. Conversely, increase of PCT is down-regulated [6] in patients with viral infections, who experience a very low or negligible increase in PCT levels [1].

Although there is still some debate on the exact mechanism of PCT and its diagnostic and prognostic potential and limitations, PCT is currently accepted as the serological marker of reference for infections and outcome for critically ill patients $[1,2,7,8]$.

So far, however, most trials in literature have tested the effectiveness of PCT exclusively on patients within the intensive care unit (ICU) and emergency department (ED), without extending findings to other patient settings, such as that of the intermediate care units (IMC), which feature peculiar demographic and clinical characteristics. Differently from the heterogeneous group of ICU and ED patients, who present a wide range of sever trauma/injury or acute conditions across all age groups, IMC patients are generally elderly patients, who present several comorbidities and chronic conditions. Such patients require a more intensive monitoring and assistance than that provided by general medical wards, but yet do not require life-support equipment/assistance (such as invasive mechanical ventilation) as in the ICU or ED. In fact, IMCs, also known as step-down units or high-dependency units $[9,10]$, admit both patients from the ICU who have been stabilized, and patients from the emergency room and general medical wards who are at higher potential risk of complications $[9,11]$. 
In the case of patients with sepsis or septic shock, the availability of reliable prognostic markers becomes fundamental in supporting quick decision-making and delivering most appropriate and timely care to most critical patients.

Here we report a prospective observational study that aimed to explore the role of PCT and its variations between admission and $72 \mathrm{~h}$ in predicting 30-day mortality in patients with severe sepsis and septic shock admitted to a medical IMC.

\section{Patients and Methods}

\section{Study design, patients, and clinical setting}

This was a prospective non-interventional observational study performed at the IMC within the Emergency and Internal Medicine Department of the Careggi Hospital in Florence (Italy).

The study considered 789 consecutive patients admitted to our unit, between November 2012 and February 2014, enrolling a total 149 patients presenting sever sepsis or septic shock, as defined by the American College of Chest Physicians/Society of Critical Care Medicine Consensus Conference [12]. Patients had been admitted directly from the ED or from general medical wards within $12 \mathrm{~h}$ from onset of sepsis, in accordance with the internationally accepted criteria for admission to IMC [11]. Patients transferred by step-down from ICU were not included in the study.

The only criterion for exclusion from the study was an incomplete profile of predetermined PCT measurements within $72 \mathrm{~h}$ since admission.

The study protocol was submitted and approved by our Local Ethics Committee and the study was performed in compliance with the principles set in the Declaration of Helsinki.

\section{Patient management and outcome measures}

Patients were admitted to our IMC, an eight-bed section within the Emergency and Internal Medicine Department, where continual patient-care is guaranteed on rotating basis by five dedicated internal medicine specialists trained in critical care medicine (covering daily shifts) who were supported by five non-dedicated internal medicine physicians for the coverage of night shifts and nursing staff distributed by a 1:4 ratio, and who are assisted by one nurse assistant during day shifts.

As foreseen by our unit's patient management protocol, patients with most severe cases of sepsis (i.e. severe sepsis and septic shock) underwent routine continuous monitoring for ECG, oximetry, respiratory rate, arterial blood pressure (non-invasive or invasive, as needed), central venous pressure (Infinity Delta, Drager, Lubeck, Germany) and regular monitoring of central venous saturation of oxygen $\left(\mathrm{ScVO}_{2}\right)$ and lactate values. Non-invasive mechanical ventilation was provided only when required. As established by the guidelines of the Surviving Sepsis Campaign [12], multiple blood and urine sample cultures were also performed (BACTEC system, Benex Limited, Shannon, Ireland). Cultures from sputum, bronchial aspirate or purulent exudates were obtained in selected cases.
Empiric antibiotic therapy was given early and later modified if necessary, based on results of cultural samples. After a first-line evaluation with a chest X-ray, abdominal ultrasound and transthoracic echocardiography, a complete thoracic and abdominal CT scan was performed. Severity of condition was classified according to three different score-systems: the mortality in emergency department sepsis (MEDS), sepsis-related organ failure assessment (SOFA), acute physiology and chronic health evaluation (APACHE) II score [13-15], plus the burden of multimorbidities with the age-adjusted Charlson comorbidity index [16]. Sepsis was considered nosocomial when onset occurred more than 2 days after hospital admission. The clinical end-point of the study was 30-day mortality.

\section{Determination of procalcitonin}

Blood samples were drawn for measurement of PCT within the first hour after admission to the IMC, and again at 24 and $72 \mathrm{~h}$. PCT was measured using the Vidas PCT kit (Brahms Diagnostics, Berlin, Germany) in accordance to manufacturer's instructions and as described elsewhere [17].

\section{Statistical analysis}

Data were expressed as mean \pm standard deviation or as proportions. Student's $t$-test was used for the comparison of normally distributed continuous data, and the Fisher's exact test for the comparison of non-continuous variables. Kinetics of PCT were defined by the variation of values between admission and $72 \mathrm{~h}$, and 24 and $72 \mathrm{~h}$. They were calculated by the ratio of the difference between the second and the first measurement divided by the first measurement, expressed as percentage (e.g. (value at $72 \mathrm{~h}$ - value on admission)/value on admission per 100]. These variables were then defined as $\Delta$-PCT0-72h and $\Delta$-PCT24-72h, respectively. A receiver-operating-characteristic (ROC) analysis was used to obtain the most accurate cut-off of single $\Delta$ values for the identification of the clinical end-point. Relative hazard (HR) of variables and 95\% confidence intervals (CIs) were calculated using univariate and multivariate logistic regression analysis. Multivariate analysis was performed using a stepwise forward regression model, with an entry probability for each variable set at 0.05 . Survival curves were constructed according to the Kaplan-Meier method. All P-values were twotailed and considered significant when $<0.05$ (95\% CI). All analyses were performed using 21.0 SPSS statistical software (SPSS, Chicago, IL).

\section{Results}

\section{Patient characteristics and outcome}

Between November 2012 and February 2014, 789 patients were admitted to our IMC. Of the 149 (19\%) patients presenting severe sepsis or septic shock, five were excluded from the study: two due to incomplete/unavailable profile of predeter- 
Table 1. Baseline Characteristics of the Overall Population and in the Two Groups of Patients Who Survived or Died at 30-Day Follow-Up

\begin{tabular}{|c|c|c|c|c|}
\hline & \multirow{2}{*}{ Overall population $(n=144)$} & \multicolumn{2}{|c|}{ Death at 30 days } & \multirow{2}{*}{$\mathbf{P}$} \\
\hline & & No $(n=103)$ & Yes $(n=41)$ & \\
\hline Age (years) & $73 \pm 14$ & $72.3 \pm 14.7$ & $74.9 \pm 12.9$ & 0.32 \\
\hline Male & $50(34.7 \%)$ & $37(35.9 \%)$ & $13(31.7 \%)$ & 0.70 \\
\hline \multicolumn{5}{|l|}{ Comorbidities } \\
\hline CHF (NYHA class III-IV) & $35(24.3 \%)$ & $25(24.3 \%)$ & $10(24.4 \%)$ & 0.99 \\
\hline COPD & $29(20.1 \%)$ & $21(20.4 \%)$ & $8(19.5 \%)$ & 0.99 \\
\hline Diabetes & $30(20.8 \%)$ & $23(22.3 \%)$ & $7(17.1 \%)$ & 0.65 \\
\hline Chronic renal failure & $26(18.1 \%)$ & $17(16.5 \%)$ & $9(22.0 \%)$ & 0.47 \\
\hline Active cancer & $23(16 \%)$ & $13(12.6 \%)$ & $10(24.4 \%)$ & 0.12 \\
\hline Hematologic malignancy & $18(12.5 \%)$ & $10(9.7 \%)$ & $8(19.5 \%)$ & 0.16 \\
\hline Chronic steroid therapy & $27(24.1 \%)$ & $15(18.8 \%)$ & $12(37.5 \%)$ & 0.05 \\
\hline Age-adjusted Charlson comorbidity index & $5.9 \pm 2.3$ & $5.7 \pm 2.4$ & $6.5 \pm 1.8$ & 0.07 \\
\hline Chronic total dependence & $42(29.2 \%)$ & $29(28.1 \%)$ & $13(31.7 \%)$ & 0.40 \\
\hline \multicolumn{5}{|l|}{ Clinical parameters } \\
\hline Heart rate (bpm) & $97 \pm 20$ & $96 \pm 19$ & $99 \pm 20$ & 0.42 \\
\hline Respiratory rate (bpm) & $19.2 \pm 6.6$ & $18.6 \pm 6.7$ & $20.7 \pm 6.4$ & 0.82 \\
\hline MAP (mm Hg) & $83.1 \pm 15.5$ & $83.2 \pm 16.5$ & $82.8 \pm 13.0$ & 0.89 \\
\hline Temperature $\left({ }^{\circ} \mathrm{C}\right)$ & $37.2 \pm 1.0$ & $37.2 \pm 1.0$ & $37.1 \pm 0.9$ & 0.34 \\
\hline $\mathrm{PaO}_{2} / \mathrm{FiO}_{2}(\mathrm{~mm} \mathrm{Hg})$ & $243.8 \pm 94.2$ & $268.7 \pm 85.6$ & $192.2 \pm 91.5$ & $<0.001$ \\
\hline \multicolumn{5}{|l|}{ Indexes of severity } \\
\hline APACHE-II (points) & $15.8 \pm 5.9$ & $14.9 \pm 5.7$ & $17.9 \pm 6.2$ & $<0.05$ \\
\hline MEDS (points) & $9.3 \pm 4.5$ & $8.2 \pm 4.1$ & $12.2 \pm 3.9$ & $<0.0001$ \\
\hline SOFA (points) & $5.7 \pm 3.5$ & $4.9 \pm 3.3$ & $7.6 \pm 3.2$ & $<0.0001$ \\
\hline Length of stay (days) & $14.6 \pm 11.2$ & $15.7 \pm 11.6$ & $11.9 \pm 9.9$ & 0.52 \\
\hline
\end{tabular}

CHF: chronic heart failure; COPD: chronic obstructive pulmonary disease; MAP: mean arterial pressure; APACHE: Acute Physiology, Age and Chronic Health Evaluation; MEDS: mortality in emergency department sepsis score; SOFA: sepsis-related organ failure assessment score.

mined PCT measurements, and three patients because of death or transfer to the ICU within $72 \mathrm{~h}$ from admission. Hence the final study population was composed of 144 patients.

As shown in Table 1 summarizing main demographic and clinical characteristics at baseline, the patient population was mostly composed of older individuals and had a high prevalence of comorbidities, with over $35 \%$ of the patients having two or more significant pre-existing diseases. Of note, a relevant proportion of patients had dementia and/or chronic total dependence. Thirty-nine percent of the population presented an age-adjusted Charlson comorbidity index $>6$. Patients with poorest outcome had the highest baseline severity of disease, independently from the scoring system used. Values of general laboratory parameters did not differ between patients who deceased within the 30 days end-point and those who survived. The most common site of infection was the lung (51.4\%) and most infections were community acquired (77\%) (Table 1). Ninety-three patients $(64.6 \%)$ had severe sepsis upon admission, while the remaining had septic shock (35.4\%). Blood cultures were positive in nearly $46 \%$ of cases, with a prevalence of Gram-negative bacteria. There was a significant prevalence of patients with multiple drug-resistant (MDR) bacterial infections (methicillin-resistant $S$. aureus, $P$. aeruginosa, A. baumannii, K. pneumoniae and S. maltophilia) accounting for $17.4 \%$ of isolated agents, with no difference between groups, nor significance at univariate analysis for prediction of mortality (HR: 2.4 ; 95\% CI: 0.9 - 6.3; P=0.08).

Overall, death within 30 days from the day of admission occurred in 41 patients $(28.5 \%)$; patients admitted with septic shock had a $35.4 \%$ mortality rate. On average, death occurred $14 \pm 12$ days from admission to the IMC (range 3 - 28 days).

\section{Biohumoral and clinical predictors of outcome}

Mean PCT values on admission were $28.06 \pm 63.29 \mathrm{ng} / \mathrm{mL}$ (range $0.05-397.92 \mathrm{ng} / \mathrm{mL}$ ) and were lower in patients who died within the 30-day timeframe (Table 2). A significant decrease of mean PCT values between admission and $72 \mathrm{~h}$ was found in survivors $(\mathrm{P}<0.001 ; 95 \% \mathrm{CI}: 8.9$ - 32.7) as compared 
Table 2. Baseline Laboratory Characteristics, Site and Type of Infection, and Isolated Microbiological Agent in the General Population and in the Groups of Patients Who Survived or Died at 30-Day Follow-Up

\begin{tabular}{|c|c|c|c|c|}
\hline & \multirow{2}{*}{$\begin{array}{l}\text { Overall popula- } \\
\text { tion }(n=144)\end{array}$} & \multicolumn{2}{|c|}{ Death at 30 days } & \multirow{2}{*}{$\mathbf{P}$} \\
\hline & & No $(n=103)$ & Yes $(n=41)$ & \\
\hline \multicolumn{5}{|l|}{ Laboratory values } \\
\hline WBC count $\left(1,000 / \mathrm{mm}^{3}\right)$ & $10.4 \pm 9.3$ & $10.9 \pm 8.4$ & $11.1 \pm 11.3$ & 0.54 \\
\hline Hemoglobin (g/dL) & $10.7 \pm 1.7$ & $11.1 \pm 2.2$ & $10.7 \pm 1.9$ & 0.29 \\
\hline Platelet count $\left(1,000 / \mathrm{mm}^{3}\right)$ & $210 \pm 143$ & $204 \pm 136$ & $223 \pm 159$ & 0.47 \\
\hline Creatinine (mg/dL) & $1.7 \pm 1.8$ & $1.9 \pm 1.7$ & $1.3 \pm 0.7$ & 0.67 \\
\hline Lactate $(\mathrm{mmol} / \mathrm{L})$ & $2.3 \pm 1.6$ & $2.4 \pm 1.9$ & $2.1 \pm 1.0$ & 0.38 \\
\hline Cardiac troponin $\mathrm{I}(\mu \mathrm{g} / \mathrm{L})$ & $0.3 \pm 0.5$ & $0.3 \pm 0.6$ & $0.1 \pm 0.3$ & 0.21 \\
\hline ProBNP (pg/mL) & $9,244 \pm 14,805$ & $9,613 \pm 16,604$ & $7,998 \pm 7,301$ & 0.66 \\
\hline PCT on admission (ng/mL) & $28.06 \pm 63.29$ & $34.1 \pm 70.1$ & $12.7 \pm 33.7$ & 0.07 \\
\hline PCT at $24 \mathrm{~h}(\mathrm{ng} / \mathrm{mL})$ & $29.09 \pm 63.28$ & $33.64 \pm 70.05$ & $16.81 \pm 37.87$ & 0.19 \\
\hline PCT at $72 \mathrm{~h}(\mathrm{ng} / \mathrm{mL})$ & $13.48 \pm 29.04$ & $13.31 \pm 31.97$ & $13.92 \pm 20.21$ & 0.91 \\
\hline \multicolumn{5}{|l|}{ Site and type of infection } \\
\hline Lung & $74(51.4 \%)$ & $47(45.6 \%)$ & $27(65.9 \%)$ & 0.04 \\
\hline Urinary tract & $32(22.2 \%)$ & $30(29.1 \%)$ & $2(4.9 \%)$ & 0.001 \\
\hline Gall bladder & $6(4.2 \%)$ & $5(4.9 \%)$ & $1(2.4 \%)$ & 0.67 \\
\hline Other & $32(22.2 \%)$ & $21(20.4 \%)$ & $11(26.8 \%)$ & 0.69 \\
\hline Septic shock & $51(35.4 \%)$ & $25(24.3 \%)$ & $26(63.4 \%)$ & $<0.0001$ \\
\hline Nosocomial & $33(22.9 \%)$ & $21(20.4 \%)$ & $12(29.3 \%)$ & 0.27 \\
\hline Community acquired & $111(77.1 \%)$ & $82(79.6 \%)$ & $29(70.7 \%)$ & 0.27 \\
\hline \multicolumn{5}{|l|}{ Isolated agent } \\
\hline Positive blood cultures & $67(46.5 \%)$ & $49(47.6 \%)$ & $18(43.9 \%)$ & 0.42 \\
\hline Gram-positive & $27(18.7 \%)$ & $17(16.5 \%)$ & $10(24.4 \%)$ & 0.26 \\
\hline Gram-negative & $30(20.8 \%)$ & $24(23.3 \%)$ & $6(14.6 \%)$ & 0.15 \\
\hline Fungi & $3(2.1 \%)$ & $2(1.9 \%)$ & $1(2.4 \%)$ & 0.77 \\
\hline Polymicrobial & $7(4.9 \%)$ & $11(10.7 \%)$ & $6(14.6 \%)$ & 0.63 \\
\hline
\end{tabular}

WBC: white blood cell count; ProBNP: pro-brain natriuretic peptide; PCT: procalcitonin.

to those who died $(\mathrm{P}=0.665 ; 95 \% \mathrm{CI}:-13.1-10.8)$. An ROC analysis identified a decrease of $\Delta$-PCT0-72h less than $15 \%$ (area under the curve: 0.75 ; 95\% CI: 0.67 - 0.82) and a decrease of $\Delta$-PCT24-72h less than $20 \%$ (area under the curve: $0.83 ; 95 \% \mathrm{CI}: 0.74-0.92$ ) as the more accurate cut-offs in predicting adverse outcome. The predictive value of $\triangle$-PCT0-72h was compared with $\triangle$-PCT24-72h through construction of the corresponding ROC curves; areas under the curve were 0.74 $(0.05)$ and $0.83(0.04)$ (mean (standard deviation)), respectively $(\mathrm{P}=0.052)$ (Fig. 1).

Results of univariate and multivariate logistic regression analysis of several demographic, clinical characteristics and biohumoral markers analysed are shown in Table 2 . Interestingly, the univariate logistic regression analysis highlighted that a decrease of $\Delta$-PCT0-72h $<15 \%$ was predictive of adverse outcome with a $6.1 \mathrm{HR}(95 \% \mathrm{CI}: 2.7-13.6$; $\mathrm{P}<0.0001)$ and that a $\triangle$-PCT24-72h $<20 \%$ was predictive of adverse outcome with a 5.9 HR $(95 \%$ CI: $2.5-14.1$; P $<0.0001)$. At mul- tivariate logistic regression analysis assessing the association of several variables with risk of 30-day mortality, $\Delta$-PCT0-72h decrease less than $15 \%$ and $\Delta$-PCT24-72h decrease less than $20 \%$ retained their independent predictive role with an HR of 3.9 (95\% CI: 1.6 - 9.5; P < 0.0001) and of 3.1 (95\% CI: 1.2 - 7.9; P $<0.001$ ), respectively (Table 3). Kaplan-Meier eventfree survival estimate curves for the corresponding $\triangle$-PCT values are shown in Figure 2.

\section{Discussion}

While many studies have validated the use of PCT for risk stratification in the ICU and the ED [18-24], the present study is the first to investigate the potential role of PCT in risk stratification on a large cohort of patients presenting severe sepsis or septic shock within the IMC setting. This aspect is particularly relevant in the European context where ICMs have a central 


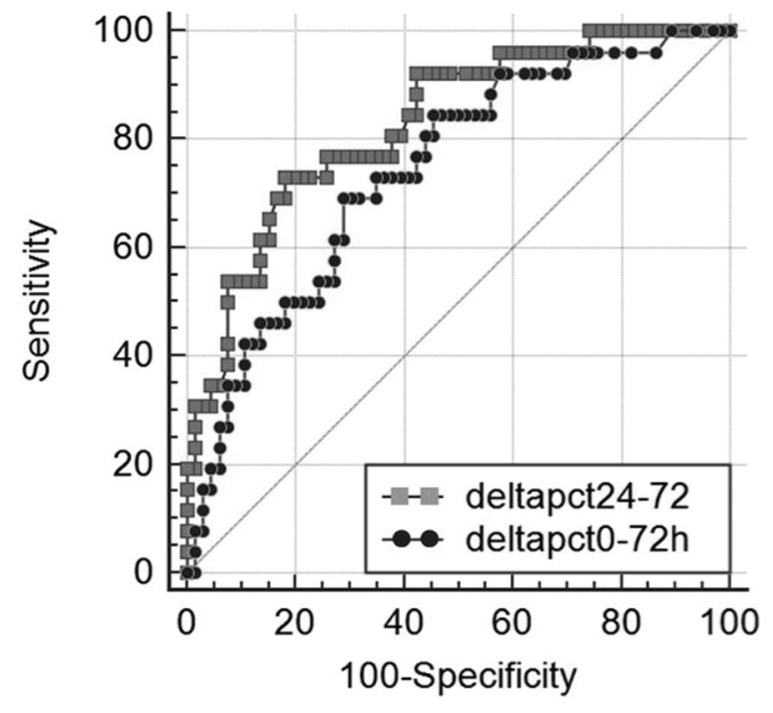

Figure 1. Receiver operating characteristic (ROC) curves of $\triangle$-PCT\% variation between day 0 and $72 \mathrm{~h}$ (black dotted line) and between 24 and $72 \mathrm{~h}$ (grey dotted line) for differentiating between 30-day survivors and non-survivors in 144 patients with severe sepsis syndromes, area under the ROC curve $=0.743(0.055)$ for and $0.83(0.046)$ (mean (standard deviation)), respectively $(P=0.052)$.

role in relieving the ICU from patient overflow; indeed, compared to other healthcare realities such as the United States, the number of ICU beds in most facilities is extremely limited compared to the patient population they are meant to serve [25, 26]. Several studies have demonstrated the convenience of implementing IMCs in support to ICUs [9], and IMCs are now slowly being established in many hospital facilities with the specific purpose of assisting/caring severely ill patients with limited organ dysfunction, advanced age, or a heavy burden of comorbidities. Hence it is important that parameters which are currently validated for other settings be reconsidered in view of this new growing hospital population.

In the present study, one major finding emerging is the identification of independent predictors of 30-day mortality, namely 1) a PCT decrease less than $15 \%$ between admission and $72 \mathrm{~h}$ and 2) a PCT decrease less than $20 \%$ between 24 and $72 \mathrm{~h}$ from onset. Such results were independent of initial severity assessment by commonly used risk score, such as APACHE II, SOFA and MEDS. At multivariate analysis patients with a decline in $\triangle$-PCT0-72h less than $15 \%$ had a 3.9 -fold risk increase of 30 day mortality and those with a decline in $\Delta$-PCT24-72h less than $20 \%$ had a 3.1 -fold increase. Conversely, absolute concentrations of PCT at baseline, and at subsequent time intervals over $72 \mathrm{~h}$, had no role in predicting 30-day mortality. Therefore, dynamic changes of PCT, rather than absolute concentrations, were predictive of adverse outcome. Our results are in agreement with those reported by Phua et al who described no value of initial PCT determination in differentiating survivors and non-survivors in a population of ICU patients with septic shock. Only a rising trend in PCT values between day 1 and 2 was predictive of 28-day mortality [27]. Similarly, in septic shock patients with initial PCT values greater than $10 \mathrm{ng} / \mathrm{mL}$,
Guan et al reported that dynamic change, instead of PCT concentrations itself, was predictive of mortality [28]. Charles et al found that a decrease of PCT greater of more than $30 \%$ between day 2 and 3 was predictive of a better outcome in a cohort of septic patients admitted to ICU [5]. More recently Schuetz et al in a retrospective study of patients with severe sepsis or septic shock admitted to US critical care units found that 72-h PCT kinetics was an accurate predictor of in-hospital mortality [29, 30]. In our study, we did not find any significant difference in PCT kinetics considered at two different time intervals; indeed there was no difference between area under the ROC curves of $\Delta$-PCT0-72h and $\Delta$-PCT24-72h $(0.74$ and 0.83 , respectively; P $=0.052)$. The superiority of kinetics rather than absolute PCT values in prognostication seems to rely on PCT physiological characteristics. There is evidence that there is little intracellular PCT storage and its production in response to bacterial infections is mostly mediated by activation of the common ancestral calcitonin gene I in parenchymal tissues [30]; this process needs time and could be the reason of the greater prognostic value of repeated PCT measurements exploring dynamic variations instead of absolute concentrations.

There are some characteristics in our cohort of patients that should be underlined. In comparison to previous studies on prognostic value of PCT in severe sepsis syndromes, our patients were significantly older and the mean age was nearly one decade higher (73 vs. 64 years) than that reported in other studies [5, 24, 27-29]. Moreover, the prevalence of comorbid conditions was high as documented by age adjusted Charlson comorbidity index greater than 6 , corresponding to an estimated 1 -year mortality of $63 \%$, in nearly $40 \%$ of the study population [16]. The 30-day mortality rate in our cohort was $28.5 \%$, a value comparable to recent data regarding severely ill septic patients admitted in European ICUs [31]. The advanced age and the burden of comorbidity could explain this finding despite a lower risk profile on admission evaluated with commonly used risk scores in sepsis (i.e. APACHE II, SOFA, MEDS) [15, 31-33]. These indexes of severity may be less reliable in a setting different from that of the ICU or ED for which they were initially developed and validated [34]. Thus, biohumoral markers, such as PCT, may have a more accurate predictive role in the setting of IMCs than risk scores [35].

Although promising, our results must however be viewed in light of some limitations within the study, such as the single center experience and the arbitrary choice of percentage changes as an indicator of PCT kinetics instead of other methods. Some authors for the purpose of similar studies considered PCT percentage changes grouped in tertiles or quartiles, while others reported specific cut-off values for PCT interpretation. Certainly, choosing in favor a specific method over another has advantages and disadvantages. For example, dividing percentage variation into tertiles or quartiles can help to understand the impact on mortality across different degrees of change, but can be more difficult to export. Moreover, dynamic changes expressed as percentage variation depend on many factors such as the starting value, and subsequent timing of PCT evaluation, on the other hand they can be easily quantified and have been used in many papers. A direct comparison of results of studies is difficult for several reasons; one among others is that all the trials on the prognostic role of biomarkers 
Table 3. Factors Predictive of In-Hospital Death at Univariate and Multivariate Logistic Regression Analysis

\begin{tabular}{|c|c|c|c|c|c|c|}
\hline & \multicolumn{3}{|c|}{ Univariate analysis } & \multicolumn{3}{|c|}{ Multivariate analysis } \\
\hline & HR & $95 \% \mathrm{CI}$ & $\mathbf{P}$ & HR & $95 \% \mathrm{CI}$ & $\mathbf{P}$ \\
\hline Age & 1.0 & $0.9-1.0$ & 0.32 & & & \\
\hline Age more than 75 years & 1.0 & $0.5-2.1$ & 0.98 & & & \\
\hline Sex (male vs. female) & 0.8 & $0.4-1.8$ & 0.70 & & & \\
\hline Diabetes & 0.7 & $0.3-1.8$ & 0.48 & & & \\
\hline Chronic heart failure & 1.0 & $0.4-2.3$ & 0.98 & & & \\
\hline COPD & 0.9 & $0.4-2.3$ & 0.90 & & & \\
\hline Chronic renal failure & 1.4 & $0.6-3.5$ & 0.44 & & & \\
\hline Cancer & 2.2 & $0.9-5.6$ & 0.87 & & & \\
\hline Hematologic malignancy & 2.2 & $0.8-6.2$ & 0.11 & & & \\
\hline Chronic total dependence & 1.2 & $0.5-2.6$ & 0.77 & & & \\
\hline Corticosteroid therapy & 2.6 & $1.0-6.4$ & 0.04 & & & \\
\hline Charlson index* & 1.2 & $1.0-1.4$ & 0.08 & & & \\
\hline Pneumonia & 2.3 & $1.1-4.9$ & 0.03 & & & \\
\hline Polymicrobial sepsis & 2.5 & $1.1-5.9$ & $<0.05$ & & & \\
\hline MDR bacteria & 2.4 & $0.9-6.3$ & 0.08 & & & \\
\hline Nosocomial acquired & 1.6 & $0.7-3.7$ & 0.27 & & & \\
\hline Septic shock on presentation & 5.4 & $2.5-11.8$ & $<0.001$ & 5.3 & $2.3-12.4$ & $<0.0001$ \\
\hline Antibiotic therapy within $6 \mathrm{~h}$ & 0.4 & $0.1-1.3$ & 0.19 & & & \\
\hline MEDS & 1.3 & $1.1-1.4$ & $<0.001$ & 1.3 & $1.1-1.5$ & 0.001 \\
\hline SOFA & 1.3 & $1.1-1.4$ & $<0.001$ & & & \\
\hline SOFA $48 \mathrm{~h}$ & 1.3 & $1.1-1.6$ & $<0.001$ & & & \\
\hline APACHE-II & 1.1 & $1.0-1.1$ & 0.02 & & & \\
\hline PCT on admission & 0.9 & $0.9-1.0$ & 0.09 & & & \\
\hline PCT at $24 \mathrm{~h}$ & 0.9 & $0.9-1.0$ & 0.22 & & & \\
\hline PCT at $72 \mathrm{~h}$ & 1.0 & $0.9-1.0$ & 0.90 & & & \\
\hline \multicolumn{7}{|l|}{$\Delta$-РCТ $\%$ variation } \\
\hline$\Delta-0-72 \mathrm{~h}$ decrease $<15 \%$ & 6.1 & $2.7-13.6$ & $<0.0001$ & 3.9 & $1.6-9.5$ & $<0.0001$ \\
\hline$\Delta-24-72 \mathrm{~h}$ decrease $<20 \%$ & 5.9 & $2.5-14.1$ & $<0.0001$ & 3.1 & $1.2-7.9$ & $<0.001$ \\
\hline
\end{tabular}

${ }^{*}$ Age-adjusted Charlson comorbidity index [19]. COPD: chronic obstructive pulmonary disease; MDR: multiple drug-resistant; MAP: mean arterial pressure; MEDS: mortality in emergency department sepsis; SOFA: sepsis-related organ failure assessment; APACHE: acute physiology, age and chronic health evaluation; PCT: procalcitonin. $\triangle$-PCT\% variation is the ratio, expressed as percentage, of the difference between the second and the first measurement divided by the first measurement (see "Methods" section for more details).

in sepsis were performed in ICU or ED and there are no available data in intermediate care setting. Furthermore, a possible limitation of the study is the exclusion of patients where PCT measurements were not available for several reasons. In our opinion this is a minor limitation since these patients were few (3.3\% of screened patients) and the study sought to evaluate PCT kinetics between admission and $72 \mathrm{~h}$ "per protocol".

In summary, our results show that a PCT decrease between admission and $72 \mathrm{~h}$ less than 15\%, and between 24 and $72 \mathrm{~h}$ less than $20 \%$, are independent predictors of 30-day mortality in severely ill septic patients admitted to a hospitalist-managed IMC. Therefore, in the broader context of other routine clinical and laboratory parameters, evaluation of PCT kinetics over the first $72 \mathrm{~h}$ is a useful tool for adverse outcome prognostication in patients with severe sepsis and septic shock admitted to an IMC. Importantly, this provides physicians additional aid in the decision-making process for care intensification and proper allocation of hospital resources.

\section{Acknowledgement}

Authors are grateful to Manuella Walker (Pencil and Papers, Italy) for the language editing of the manuscript and to all staff 

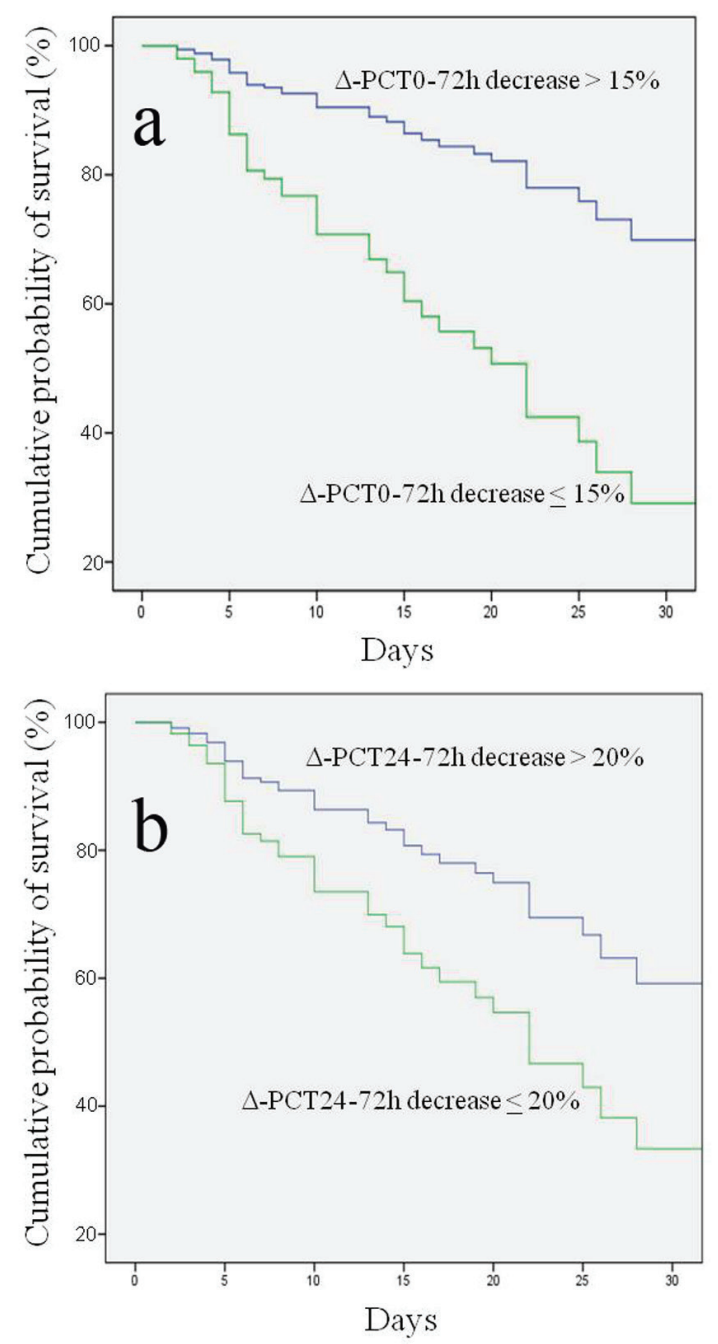

Figure 2. Kaplan-Meier estimation of probability of survival curves for different procalcitonin percentage variations $(\Delta-\mathrm{PCT})$ at different time intervals. (a) $\triangle$-PCT percentage decrease between day 0 and $72 \mathrm{~h}$ greater or less than $15 \%$ in predicting survival; log rank test $P<0.000$; $95 \% \mathrm{Cl}: 29.8$ - 41.3. (b) $\Delta$-PCT percentage decrease between 24 and $72 \mathrm{~h}$ greater or less than $20 \%$ in predicting survival; log rank test $\mathrm{P}<$ $0.0001 ; 95 \% \mathrm{Cl}: 11.4-27.8$.

members that provided daily care of patients.

\section{Conflict of Interest}

There is no conflict of interest.

\section{References}

1. Henriquez-Camacho C, Losa J. Biomarkers for sepsis. Biomed Res Int. 2014;2014:547818.

2. Assicot M, Gendrel D, Carsin H, Raymond J, Guilbaud J, Bohuon C. High serum procalcitonin concen- trations in patients with sepsis and infection. Lancet. 1993;341(8844):515-518.

3. Meynaar IA, Droog W, Batstra M, Vreede R, Herbrink P. In Critically Ill Patients, Serum Procalcitonin Is More Useful in Differentiating between Sepsis and SIRS than CRP, Il-6, or LBP. Crit Care Res Pract. 2011;2011:594645.

4. Nobre V, Harbarth S, Graf JD, Rohner P, Pugin J. Use of procalcitonin to shorten antibiotic treatment duration in septic patients: a randomized trial. Am J Respir Crit Care Med. 2008;177(5):498-505.

5. Charles PE, Tinel C, Barbar S, Aho S, Prin S, Doise $\mathrm{JM}$, Olsson NO, et al. Procalcitonin kinetics within the first days of sepsis: relationship with the appropriateness of antibiotic therapy and the outcome. Crit Care. 2009;13(2):R38.

6. Gilbert DN. Use of plasma procalcitonin levels as an adjunct to clinical microbiology. J Clin Microbiol. 2010;48(7):2325-2329.

7. Marshall JC. Measurements in the intensive care unit: what do they mean? Crit Care. 2003;7(6):415-416.

8. Jain S, Sinha S, Sharma SK, Samantaray JC, Aggrawal P, Vikram NK, Biswas A, et al. Procalcitonin as a prognostic marker for sepsis: a prospective observational study. BMC Res Notes. 2014; 7:458.

9. Armory M, Chan C, Zhu B. Critical care in Hospitals: When to introduce a Step Down unit. Available at: http:// www.columbia.edu/ cc3179/icusdu_2014.pdf. Last accessed 30 Dec 2014.

10. Solberg B, Dirksen C, Nieman F, et al. Introducing Integrated Intermaediate care unit improves ICU utilization: a prospective intervention study. BMC Anestesiology. 2014; $14: 76$.

11. Nasraway SA, Cohen IL, Dennis RC, Howenstein MA, Nikas DK, Warren J, Wedel SK. Guidelines on admission and discharge for adult intermediate care units. American College of Critical Care Medicine of the Society of Critical Care Medicine. Crit Care Med. 1998;26(3):607-610.

12. Dellinger RP, Levy MM, Rhodes A, Annane D, Gerlach H, Opal SM, Sevransky JE, et al. Surviving sepsis campaign: international guidelines for management of severe sepsis and septic shock: 2012. Crit Care Med. 2013;41(2):580637.

13. Shapiro NI, Wolfe RE, Moore RB, Smith E, Burdick E, Bates DW. Mortality in Emergency Department Sepsis (MEDS) score: a prospectively derived and validated clinical prediction rule. Crit Care Med. 2003;31(3):670675.

14. Minne L, Abu-Hanna A, de Jonge E. Evaluation of SOFA-based models for predicting mortality in the ICU: A systematic review. Crit Care. 2008;12(6):R161.

15. Knaus WA, Draper EA, Wagner DP, Zimmerman JE. APACHE II: a severity of disease classification system. Crit Care Med. 1985;13(10):818-829.

16. Charlson M, Szatrowski TP, Peterson J, Gold J. Validation of a combined comorbidity index. J Clin Epidemiol. 1994;47(11):1245-1251.

17. Jin M, Khan I. Procalcitonin: Uses in the Clinical Laboratory for the Diagnosis of sepsis. Lab Medicine. 2010;41(3):173-177. 
18. Castelli GP, Pognani C, Meisner M, Stuani A, Bellomi D, Sgarbi L. Procalcitonin and C-reactive protein during systemic inflammatory response syndrome, sepsis and organ dysfunction. Crit Care. 2004;8(4):R234-242.

19. Becker KL, Snider R, Nylen ES. Procalcitonin assay in systemic inflammation, infection, and sepsis: clinical utility and limitations. Crit Care Med. 2008;36(3):941-952.

20. Balc IC, Sungurtekin H, Gurses E, Sungurtekin U, Kaptanoglu B. Usefulness of procalcitonin for diagnosis of sepsis in the intensive care unit. Crit Care. 2003;7(1):8590.

21. Brunkhorst FM, Wegscheider K, Forycki ZF, Brunkhorst R. Procalcitonin for early diagnosis and differentiation of SIRS, sepsis, severe sepsis, and septic shock. Intensive Care Med. 2000;26(Suppl 2):S148-152.

22. Nguyen HB, Rivers EP, Knoblich BP, Jacobsen G, Muzzin A, Ressler JA, Tomlanovich MC. Early lactate clearance is associated with improved outcome in severe sepsis and septic shock. Crit Care Med. 2004;32(8):1637-1642.

23. Park JH, Wee JH, Choi SP, Oh SH. The value of procalcitonin level in community-acquired pneumonia in the ED. Am J Emerg Med. 2012;30(7):1248-1254.

24. Lee CC, Chen SY, Tsai CL, Wu SC, Chiang WC, Wang JL, Sun HY, et al. Prognostic value of mortality in emergency department sepsis score, procalcitonin, and Creactive protein in patients with sepsis at the emergency department. Shock. 2008;29(3):322-327.

25. Carmona-Torre F, Martinez-Urbistondo D, Landecho MF, Lucena JF. Surviving sepsis in an intermediate care unit. Lancet Infect Dis. 2013;13(4):294-295.

26. Halpern NA, Pastores SM. Critical care medicine in the United States 2000-2005: an analysis of bed numbers, occupancy rates, payer mix, and costs. Crit Care Med. 2010;38(1):65-71.

27. Phua J, Koay ES, Lee KH. Lactate, procalcitonin, and amino-terminal pro-B-type natriuretic peptide versus cytokine measurements and clinical severity scores for prognostication in septic shock. Shock. 2008;29(3):328333.

28. Guan J, Lin Z, Lue H. Dynamic change of procalcitonin, rather than concentration itself, is predictive of survival in septic shock patients when beyond $10 \mathrm{ng} / \mathrm{mL}$. Shock. 2011;36(6):570-574.

29. Schuetz P, Maurer P, Punjabi V, Desai A, Amin DN, Gluck E. Procalcitonin decrease over 72 hours in US critical care units predicts fatal outcome in sepsis patients. Crit Care. 2013;17(3):R115.

30. Muller B, White JC, Nylen ES, Snider RH, Becker KL, Habener JF. Ubiquitous expression of the calcitonin-i gene in multiple tissues in response to sepsis. J Clin Endocrinol Metab. 2001;86(1):396-404.

31. Levy MM, Artigas A, Phillips GS, Rhodes A, Beale R, Osborn T, Vincent JL, et al. Outcomes of the Surviving Sepsis Campaign in intensive care units in the USA and Europe: a prospective cohort study. Lancet Infect Dis. 2012;12(12):919-924.

32. Hermans MA, Leffers P, Jansen LM, Keulemans YC, Stassen PM. The value of the Mortality in Emergency Department Sepsis (MEDS) score, C reactive protein and lactate in predicting 28-day mortality of sepsis in a Dutch emergency department. Emerg Med J. 2012;29(4):295300.

33. Le Gall JR, Lemeshow S, Saulnier F. A new Simplified Acute Physiology Score (SAPS II) based on a European/North American multicenter study. JAMA. 1993;270(24):2957-2963.

34. Giannazzo G, Tola F, Vanni S, Bondi E, Pepe G, Grifoni S. Prognostic indexes of septic syndrome in the emergency department. Intern Emerg Med. 2006;1(3):229-233.

35. Schuetz P, Wolbers M, Christ-Crain M, Thomann R, Falconnier C, Widmer I, Neidert S, et al. Prohormones for prediction of adverse medical outcome in community-acquired pneumonia and lower respiratory tract infections. Crit Care. 2010;14(3):R106. 